\title{
The Politics of Ambiguity
}

\section{Citation}

Alesina, Alberto and Alex Cukierman. 1990. The Politics of Ambiguity. Quarterly Journal of Economics 105(4): 829-850.

\section{Published Version}

http://dx.doi.org/10.2307/2937875

\section{Permanent link}

http://nrs.harvard.edu/urn-3:HUL.InstRepos:4552530

\section{Terms of Use}

This article was downloaded from Harvard University's DASH repository, and is made available under the terms and conditions applicable to Other Posted Material, as set forth at http:// nrs.harvard.edu/urn-3:HUL.InstRepos:dash.current.terms-of-use\#LAA

\section{Share Your Story}

The Harvard community has made this article openly available.

Please share how this access benefits you. Submit a story.

Accessibility 


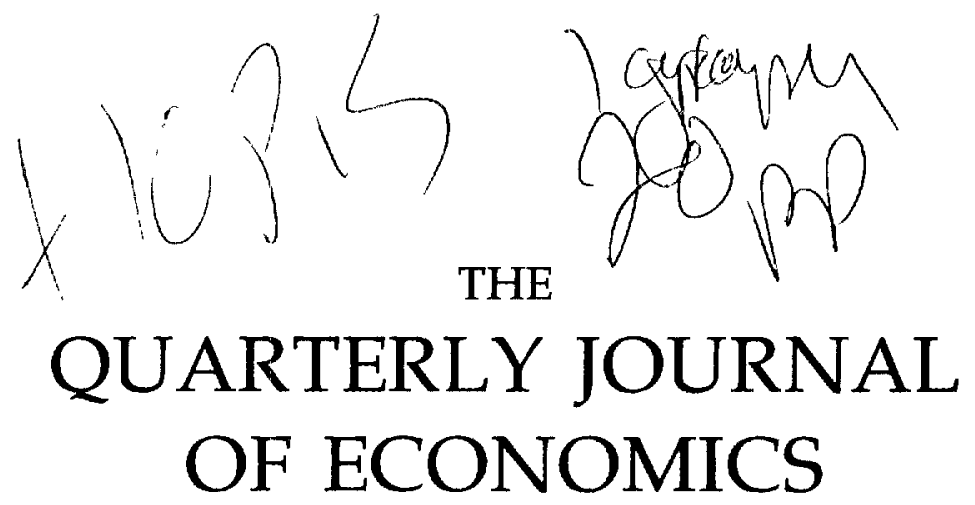

Vol. CV November $1990 \quad$ Issue 4

THE POLITICS OF AMBIGUITY*

Alberto Alesina ANd Alex Cukierman

Politicians face a trade-off between the policies that maximize their chances of reelection and their most preferred policies (or the policies most preferred by the constituency which they represent). This paper analyzes this trade-off in a dynamic electoral model in which the voters are not fully informed about the preferences of the incumbent. First, we show that the incumbent follows a policy which is intermediate between the other party's ideal policy and his own ideal policy. Second, we show that, often, the incumbent has an incentive to choose procedures which make it difficult for voters to pinpoint his preferences with absolute precision Thus, politicians may prefer to be "ambiguous."

\section{INTRODUCTION}

Politicians are motivated by two objectives: on the one hand, they care about their appointment; on the other hand, they represent the interests of their own constituencies. Thus, politicians face a trade-off between the policies that maximize their chances of reelection and those that are most preferred by the constituency supporting their party.

Most of the literature based upon the contribution of Downs [1957] exclusively emphasizes the first motive: when politicians are only "office motivated," one should observe complete policy conver-

*We would like to thank Avi Ben-Zvi; Nancy Bermeo; John Ferejohn; Stanley Kelley, Jr.; Kenneth Shepsle; David Scharfatein; an anonymous referee; the Editorial Board of this Journal, and the participants in seminars at Carnegie-Mellon University, Harvard University, the University of Rochester, Hoover Institution, Tel-Aviv University, and in the conference on Economic Theories of Politics at Haifa for many useful comments; and Phil Swagel for research assistance. Substantial revisions were performed while Alesina was an Olin Fellow at the NBER. He gratefully acknowledges financial support from the Olin and Sloan Foundations

1990 by the President and Fellows of Harvard College and the Massachusetts Institute of Technology.

The Quarterly Journal of Economics, November 1990 
gence in a two-party system. ${ }^{1}$ Instead, if one considers the interplay of the two motives, complete policy convergence in general is not the electoral equilibrium [Wittman, 1983; Calvert, 1985].

This paper analyzes the trade-off between the preferences of the party (or candidate) and its popularity in a two-period model in which voters are not fully informed about the preferences of the incumbent. Voters observe the consequences of the policy actions taken by the party in office but not the actual actions directly. Since observable outcomes and policy actions are positively, albeit imperfectly, correlated, policy outcomes convey some information to voters about the incumbent's preferences. Because of this asymmetry in information, policymakers can strategically influence future electoral outcomes, even if voters are aware of their incentives. In general, the incumbent has an interest in retaining his information advantage; thus, he may choose to retain a certain degree of ambiguity in his procedures.

Our analysis builds upon work by Alesina [1987, 1988] and Cukierman and Meltzer [1986b]. Alesina [1988] emphasizes the difference between announcements and actual policies in a finitely repeated electoral game with rational and informed voters. If voters are perfectly informed about the objectives of the two parties, they will not believe any pre-electoral policy announcements other than those that reflect the true preferences of the parties. Thus, the parties are locked into their "ideological position," their most preferred policy, even if they attribute an extremely low weight to their ideology relative to their "love for office."

In this paper we consider a more realistic situation in which the voters are not perfectly informed about the preferences of politicians. In the first period the incumbent can choose to implement its most preferred policy or to move toward the other party's ideal point to increase its chances of reappointment. At the end of the period elections are held, and in the last period the elected party follows its ideal policy, since there is no future. ${ }^{2}$

Two sets of results are shown. First, we characterize the equilibrium policy in the first period. We show that the distance

1. The most famous result of policy convergence in a two-party system is the "median voter theorem" [Downs, 1957]

2. Lott and Reed [1987] also consider a model of electoral competition with asymmetric information Unlike in the present paper they assume that all voters have the same preferences and that their expectation formation mechanism is not "rational." Also, they do not consider as endogenous the choice of the level of ambiguity. 
between the incumbent bliss point and the actual policy is positively correlated with the weight attributed to the utility of being reappointed to the "ideology," to the discount factor (subject to some restrictions), and to the degree of "persistence" of the party's preferences, defined as the correlation of future preferences of the incumbent with current preferences.

Second, we consider the choice of the level of "ambiguity," defined as the variance of the "noise" between the policy outcome observed by voters and the policy instrument chosen by politicians. The incumbent may choose procedures that are less precise than what is technologically feasible. Higher ambiguity or less precision enables the policymaker to exploit the trade-off between his ideology and the likelihood of reappointment. By contrast, with no ambiguity the policymaker is locked into his ideological position, because voters see through his intentions. This result generalizes and modifies well-known results by Shepsle [1972].

We argue that the model is consistent with a variety of empirical observations relating to retrospective voting, the effect of public opinion on policy outcomes, and the choice of legislative procedures. It is also consistent with specific instances of deliberate fuzzing of policy positions by incumbents.

The basic model is presented in Section II. The optimization problem of the incumbent is solved in Sections III and IV. Section V considers the endogenous determination of ambiguity. Section VI discusses some empirical evidence consistent with the model. The last section concludes.

\section{THE MODEL}

The two parties denoted " $x$ " and " $y$ " care about the issues as well as about being in office. They represent the interest of different constituencies, and thus adopt the objectives of those constituencies as their own. The parties also benefit from being in office per se.

When the two parties care only about the issues, their unidimensional objective functions are given by equations (1) and (2), respectively, which will sometimes be referred to as the "ideology" of the two parties. The quadratic specification is adopted for simplicity, but any single peaked and concave utility function could be used:

$$
U(z)=-\frac{1}{2} \sum_{t=0}^{1} q^{t}\left(z_{t}-c_{t}\right)^{2} \quad \text { for party } x ; \quad 0<q \leq 1 ;
$$




$$
V(z)=-\frac{1}{2} \sum_{t=0}^{1} q^{t} \quad z_{t}^{2} \text { for party } y
$$

The policy issue is represented by $z$; the discount factor $q$ is identical for the two parties. The bliss point of party $y$ is constant over time and is normalized to zero. There is no loss of generality in this normalization: what is important is simply that the two parties' bliss points are different. The bliss point of party $x$ can change over time: its stochastic behavior is given by

$$
\begin{aligned}
& c_{t}=\bar{c}+\eta_{t} ; \quad \bar{c}>0 ; \\
& \eta_{t}=\rho \eta_{t-1}+\epsilon_{t} ; \quad 0<\rho \leq \mathbf{1} .
\end{aligned}
$$

The random variable $\epsilon$ is distributed uniformly between $-b_{\epsilon}$ and $b_{\epsilon}$ $\left(b_{\epsilon}>0\right)$ and therefore has zero mean. Also, $b_{\epsilon}$ is such that the realization of $c_{t}$ for any $t$ is positive, i.e., on the right of party $y$ 's bliss point. "The "persistence" in tastes, captured by $\rho$, is crucial for the solution of the model because it implies that the current policy of party $x$ contains information about its future objectives. The case of a taste shock occurring only in the first period $\left(\epsilon_{2} \equiv 0\right)$ can be easily handled as a special case. In addition to (1) and (2), the two parties may also attribute a positive utility to being in office per se.

When a party is in office, it chooses a policy instrument to affect the policy outcome $z$. Instruments and outcomes are linked by the following linear stochastic relations:

$$
\begin{array}{ll}
z_{t}=x_{t}+u_{t} & \text { if party } x \text { is in office; } \\
z_{t}=y_{t}+u_{t} & \text { if party } y \text { is in office, }
\end{array}
$$

where " $x$ " and " $y$ " are the choices of policy instruments of the two parties when in office and $u_{t}$ is distributed independently of $\epsilon_{t}$ and has mean zero and variance $\sigma_{u}^{2}$. Equations (5) and (6) capture in a simple way the idea of imperfect control of the policy outcome. For instance, in the case of economic policy, imperfect control may be due to the fact that the economic relationship between instrument and target is stochastic. More generally, $u_{t}$ represents any "noise" between the policy action taken by the party in office and the final outcome. Since the relation between instrument and target is the same for both parties, we are assuming the same degree of

3 Assuming with no loss of generality that $c_{1}=\bar{c}$, a sufficient condition for $c_{1}$ to be positive is $\bar{c}>b_{t}(1+\rho)$ 
"competence" for the two parties. ${ }^{4}$ For the moment we assume that $\sigma_{u}^{2}$ is given exogenously; in Section $V$ we consider the case in which $\sigma_{u}^{2}$ can be chosen by the incumbent.

Elections are held at the end of period 0 so that a "period" is defined by a term in office. The voters are rational and forward looking and have single-peaked preferences on $z$. Each voter has a different bliss point and votes for the party that is expected to follow the policy closest to his bliss point. Voters' expectations are indicated by

$$
x_{t}^{e}=E^{v}\left(x_{t} / I_{t-1}\right) ; \quad y_{t}^{e}=E^{v}\left(y_{t} / I_{t-1}\right),
$$

where $E^{v}(\cdot)$ represents the optimal linear predictor of $x_{t}$ based upon the information set of voters. Thus, $x_{t}^{e}$ and $y_{t}^{e}$ are the rational expectations of $x_{t}$ and $y_{t}$ based upon the information set available at time $t-1, I_{t-1}$, subject to the constraint of linearity of the predictor. An expected utility function of voters that is consistent with such a specification is presented in Section III. The only source of asymmetric information in the model is that party $x$ can directly observe pastand current realizations of $\eta$, while the public observes only a noisy indicator of $\eta$, namely $z_{0}$. Everything else is "common knowledge."

The distribution of voters' bliss points and, in particular, the location of the median voter is not known with certainty. This uncertainty is captured by the following function, which is "common knowledge":

$$
P=P\left(x_{1}^{e}, y_{1}^{e}\right)
$$

$P(\cdot)$ is the probability of electing party $x$ for period 1 as a function of the expectations of voters. The following restrictions are imposed on this function:

(i) $0 \leq P\left(x_{1}^{e}, y_{1}^{e}\right) \leq 1 ; \quad x_{1}^{e}, y_{1}^{e} \in R$;

(ii) $P\left(x_{1}^{e}, y_{1}^{e}\right)$ is continuous and differentiable everywhere, except possibly along the diagonal (i.e., for $x_{1}^{e}=y_{1}^{e}$ );

$$
\text { (iii) } \begin{aligned}
\frac{\partial P}{\partial x_{1}^{e}} \equiv P_{x_{1}^{e}}<0 \quad \text { if and only if } x_{1}^{e}>y_{1}^{e} ; \\
\frac{\partial P}{\partial y_{1}^{e}}=P_{y_{1}^{e}}>0 \quad \text { if and only if } x_{1}^{e}>y_{1}^{e} .
\end{aligned}
$$

4. More generally, one party may have better control of the policy instrument than the other party. On this point see Cukuerman [1990], Cukierman and Meltzer [1986a], Rogoff [1990], and Rogoff and Sibert [1988] 
Assumption (iii) implies that if one party converges toward the other, it increases its chances of election. A particular form of (8) is derived from the underlying preferences of voters in the next section.

\section{The Parties' Optimization Problem}

When in office during period 0 , party $x$ faces the following problem:

$$
\text { (9) } \begin{aligned}
& \max _{x_{0}} E^{G}[-\frac{\alpha}{2}\left(x_{0}+u_{0}-\bar{c}-\eta_{0}\right)^{2}+\dot{q}\left\{\left(P\left(x_{1}^{e}, y_{1}^{e}\right)\right.\right. \\
& \times\left[-\frac{\alpha}{2}\left(x_{1}+u_{1}-c_{1}\right)^{2}\right]+\left(1-P\left(x_{1}^{e}, y_{1}^{e}\right)\right) \\
&\left.\left.\quad \times\left[-\frac{\alpha}{2}\left(y_{1}+u_{1}-c_{1}\right)^{2}\right]+P\left(x_{1}^{e}, y_{1}^{e}\right)(1-\alpha) h\right\}\right] .
\end{aligned}
$$

In (9) $E^{G}$ is the mathematical expectation operator conditional on the information set available to the incumbent. The parameter $\alpha \epsilon[0,1]$ represents the weight attributed to the "ideology" versus the benefit of reappointment per se, indicated by $h>0$. Both $\alpha$ and $h$ are common knowledge. Note that when $\alpha=0$, we are in the case of a purely Downsian party; $\alpha=1$ implies a purely "ideological" party. The model thus accounts for the two extremes and all intermediate cases. ${ }^{5}$

To insure time consistency, we solve this problem by backward induction. If party $x$ is elected for period 1 , its policy is determined by

$$
\max _{x_{1}}-(\alpha / 2) E^{G}\left(x_{1}+u_{1}-c_{1}\right)^{2} .
$$

The solution is

$$
x_{1}=c_{1} .
$$

Analogous arguments imply that if $y$ is elected, it chooses $y_{1}=0$. Thus, by rationality of expectations,

$$
y_{1}^{e}=0 ; \quad x_{1}^{e}=E^{v}\left(x_{1} / I_{0}\right)=E^{v}\left(c_{1} / I_{0}\right) .
$$

5. The case $\alpha=0$ is not explicitly developed here since all the standard "Downsian" results apply in this case. 
Thus, in the last period of the game, there is no policy convergence. ${ }^{6}$ Using (11) and (12), the first-order condition for problem (9) is given by

$$
x_{0}=c_{0}+q P_{x_{1}^{e}}(\cdot) \frac{\partial x_{1}^{e}}{\partial x_{0}}\left[\left(\frac{1}{2}\right) E^{G}\left(c_{1}^{2}\right)+\frac{1-\alpha}{\alpha} h\right],
$$

where $c_{0}$ is the "myopic ideological position," which is the policy that would be followed by a party that cares only about the present. Equation (13) shows that so long as the future is not completely discounted $(q>0)$, the probability distribution of electoral outcomes is nondegenerate $\left(P_{x_{1}^{e}} \neq 0\right)$ and current policy affects voters expectations of future policy $\left(\partial x_{1}^{e} / \partial x_{0} \neq 0\right)$, the myopic ideological position is not chosen by party $x$. By contrast, if $\partial x_{1}^{e} / \partial x_{0}=0$, i.e., there is no influence of the current policy on voters' expectations, the "myopic ideological position" is chosen regardless of the value of all other parameters. If the effect of the current policy choice on voters' expectations is positive $\left(\partial x_{1}^{e} / \partial x_{0}>0\right), x_{0}$ is smaller than the myopic solution. By choosing more "moderate" policies than those it prefers the most, the incumbent appears to voters as being less extreme than it really is, increasing its chances of reelection in the next period.

In order to obtain further insights on the microfoundations underlying the probability function in (8), we make the following assumptions:

A.1. The expected utility of each voter from a given party depends negatively on the absolute value of the distance between the voter's ideal point and the optimal linear predictor of the party's position.

A.2. The expected utility of each voter from a given party is negatively related to the mean square deviation of the candidate's policy outcome from the linear predictor of this policy (denoted by $V$ ).

A.3. The probability distribution of the position of the ideal point of the decisive median voter is uniform between the points $a<0$ and $b>^{\prime} 0$.

6. This result may capture the effects of "finite political lives" of individual candidates - for example, an American President in his second term of office. Alesina and Spear [1988] investigate the relationship between individual candidates with finite lives and the party as an infinitely lived organization 
A.4. For all relevant values of $x_{1}^{e}$ and of $V$, there are always some voters who strictly prefer the right-wing candidate and for $x_{1}^{e}$ sufficiently close to zero but positive, the probability that this candidate is elected is positive.

It is shown in Appendix 1 that under these assumptions the function $P\left(x_{1}^{e}, 0\right)$ can be written as

$$
P\left(x_{1}^{e}, 0\right)=\left\{\begin{array}{ll}
K_{u}-k x_{1}^{e} & \frac{K_{u}}{k} \geq x_{1}^{e}>0 \\
1 / 2 & x_{1}^{e}=0 \\
0 & x_{1}^{e}>\frac{K_{u}}{k}
\end{array}\right\},
$$

where

$$
K_{u} \equiv \frac{2 b-\delta V}{2(b-a)} ; \quad 0<K_{u}<1 ; \quad k \equiv \frac{1}{2(b-a)}>0 .
$$

Needless to say, (14) satisfies the assumptions on the function $P\left(x_{1}^{e}, y_{1}^{e}\right)$ given after equation (8) and can be represented as in Figure I. Note the discontinuity at $x_{1}^{e}=0$. At this point the expected policies of the two parties are identical, and thus $P=1 / 2$. The discontinuity arises because if party $x$ crosses zero, it becomes the left-wing party, captures the left-wing electorate, and loses the right-wing voters. However, we imposed $x_{1}>0$; and since voters know this information, it follows that $x_{1}^{e}>0$ for any $x_{0}$. We can therefore restrict the derivation and the presentation of $P($.$) to the$ positive range of $x_{1}^{e .7}$ Voters compute the optimal linear predictor of $z_{1}$ :

$$
x_{1}^{e}=E^{v}\left(x_{1} \mid z_{0}\right)=f+d z_{0},
$$

where $d$ and $f$ are constants determined by the requirement that $x_{1}^{e}$ is a linear minimum variance unbiased estimate of $x_{1}$ given the observation on $z_{0}$. Given (5) and since $u$ is independent of $x$, this is also the optimal linear predictor of $z_{1}$. It is shown in Appendix 2 that $d$ and $f$ are implicitly determined by

$$
d=\frac{\rho b_{\epsilon}^{2}}{\left(q k \rho^{2} b_{\epsilon}^{2}\right)^{2} d^{2} / 15+(1-q k \rho \bar{c} d)^{2} b_{\epsilon}^{2}+q k \rho^{2} b_{\epsilon}^{2} \bar{c}+3 \sigma_{u}^{2}}
$$

7 Note that in Figure I we have that $\lim _{x_{1}^{e} \rightarrow 0+} P\left(x_{1}^{e}, 0\right)>1 / 2$ and $\lim _{x_{1}^{e} \rightarrow 0} P\left(x_{1}^{e}, 0\right)<$ $1 / 2$ (not shown) We could have the opposite situation with no change in results. Which of the two cases applies depends on the distribution of voters' preferences. 


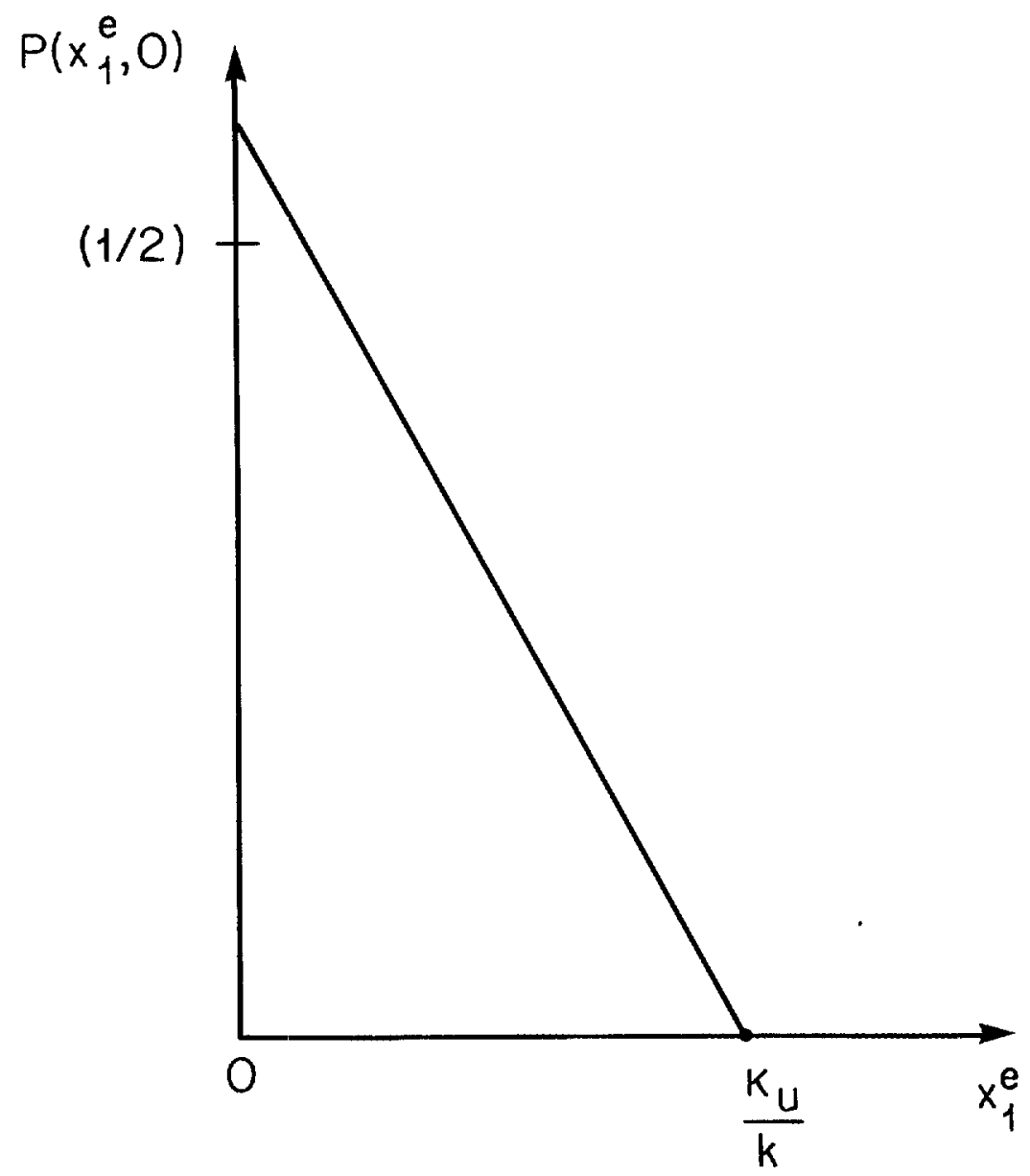

FiguRE I

(17) $f=(1-d) \bar{c}+q k\left[(1 / 6)\left(3 \bar{c}^{2}+\left(1+\rho^{2}\right) b_{\epsilon}^{2}\right)\right.$

$$
+((1-\alpha) / \alpha) h] d^{2} .
$$

Since $d$ is the solution to a third degree polynomial, there is, in general, a multiplicity of solutions for $f$ and $d$. But under a weak sufficient condition that appears in Appendix 2 and that we assume to be satisfied, there is a unique real pair of solutions for $d$ and $f$. 


\section{The Equilibrium}

By substituting (14) and (15) into (13), the policy chosen in equilibrium by the incumbent party can be rewritten as

$$
x_{0}=c_{0}-\left[(1 / 2) E^{G}\left(c_{1}^{2}\right)+((1-\alpha) / \alpha) h\right] q k d .
$$

Equations (16) through (18) have the following plausible implications:

1. Since $d>0, x_{0}<\vec{c}+\eta_{0}$. This verifies that party $x$ follows a policy that is more moderate than its bliss point in order to increase its chances of reelection. Note that $x_{0}$ may be either positive or negative. The case $x_{0}>0$ is the more natural: it implies partial convergence from the bliss point of party $x$ to the bliss point of party $y$. However, the case $x_{0} \leq 0$ cannot be ruled out. Thus, for instance, a "left-wing" government may be even more conservative than its opponent in order to influence the electorate!

2. An increase in $h$ unambiguously reduces $x_{0}$; from (18) it follows immediately that $\partial x_{0} / \partial h<0$. A higher $h$ implies that the incumbent has a stronger incentive to move away from its bliss point, trading off "ideology" for chances of reelection. However, note that voters will take account of this effect in computing $x_{1}^{e}$ if they know that $h$ has increased. In fact, one obtains ${ }^{8}$

$$
\frac{d x_{1}^{e}}{d h}=\frac{\partial f}{\partial h}+d \frac{\partial x_{0}}{\partial h}=0 .
$$

3. When $\rho$ tends to zero, $d$ also goes to zero. If there is low persistence in the incumbent's ideological position, the voters assign a low weight to their observation of $z_{0}$. As a result, the incumbent has little incentive to deviate from his ideological position.

4. The effects on $x_{0}$ of changes in the discount factor $(q)$, the variance of the noise $\left(\sigma_{u}^{2}\right)$, and the variance of the innovation in party $x$ 's preferences $\left(b_{\xi}\right)$ are ambiguous in general. Consider, for instance, an increase in $q$. On the one hand, party $x$ has an incentive to converge more because it cares more about future prospects of reappointments. On the other hand, changes in $q$ affect voters' perceptions (via $d$ ), and thus, indirectly, the choice of $x_{0}$. Due to the nonlinearity of $d$, it is impossible to sign the total derivative of $x_{0}$ with respect to $q$. Analogous considerations hold for the effects of

8. This result may ratıonalize why politicians always deny that they are eager to be elected for selfish reasons. 
changes in $k$ and $\sigma_{u}^{2}$ on $x_{0}$. The direct effect of an increase in $k$ is to move $x_{0}$ away from the party $x$ bliss point. In fact, if $k$ increases, the trade-off between "ideology and popularity" changes in a way that makes it advantageous to sacrifice more "ideology" today in exchange for an increase in chances of reelection. The indirect, and generally ambiguous, effect works through the effect of a change in $k$ on the parameter $d$ of the optimal voters' forecast.

\section{The Benefit of Ambiguity}

At the beginning of the game, before it learns the realization of its "taste shock" $\left(\epsilon_{0}\right)$ in period 0 , party $x$ can choose between alternative policy procedures that imply different levels of precision in the implementation of policy. ${ }^{9}$ Suppose that there exists a possibly small, but strictly positive, minimum level of $\sigma_{u}^{2}$, indicated by $\underline{\sigma}_{u}^{2}$, and that party $x$ can choose any level of $\sigma_{u}^{2}$ that is larger than or equal to $\sigma_{u}^{2}$.

Consider the maximum utility that can be reached by party $x$ for any given level of $\sigma_{u}^{2}$. This indirect utility function, denoted $J\left(\sigma_{u}^{2}\right)$, can be obtained by using (5), (12), (14), and (15) in (9). Since the party in office has to pick $\sigma_{u}^{2}$ before it learns the realizations of its "taste shocks," this choice is based on the (unconditional) expected value of $J(\cdot)$. Taking the expected value of $J(\cdot)$ and using the fact that $u$ and $\epsilon$ are statistically independent, we obtain ${ }^{10}$

$$
\begin{aligned}
E J\left(\sigma_{u}^{2}\right)=-E( & \left.x_{0}-c_{0}\right)^{2}-(1+q) \sigma_{u}^{2}-q E c_{1}^{2} \\
& +q E\left(K_{u}-k\left[f+d x_{0}\right]\right)\left(c_{1}^{2}+2((1-\alpha) / \alpha) h\right) .
\end{aligned}
$$

Note that in addition to being directly dependent on $\sigma_{u}^{2}, E J(\cdot)$ also depends on it indirectly, since $d, f$, and $x_{0}$ all depend on $\sigma_{u}^{2}$ (see equations (16)-(18)). Hence, except for $q E c_{1}^{2}$, all the terms in (20) depend on $\sigma_{u}^{2}$. The first expression is generally negative because party $x$ deviates from its bliss point in period 0 in order to increase its reelection prospects in period 1 . The benefit from the increased likelihood of reelection is given by the last term on the right-hand side of (20). This term is nonnegative and generally strictly positive.

9. If party $x$ could choose $\sigma_{u}^{2}$ after the realization of the shock, it would in doing so reveal information to the voters In this specification of the model, this would eliminate any asymmetry of unformation. In a more general setting with additional sources of asymmetric information, the choice of $\sigma_{u}^{2}$ after the realization of $\epsilon_{0}$ would not fully reveal everything about party $x$.

10. $E J(\cdot)$ is the expectation of the indirect objective function after multiplication by $2 / \alpha$. We also use the simplifying and innocuous assumption that $c_{-1}=\bar{c}$ 
The term $-(1+q) \sigma_{u}^{2}$ represents the direct costs of imprecise policy procedures in both periods.

The expected value of the indirect objective function of the incumbent at $\sigma_{u}^{2}$ is $E J\left(\sigma_{u}^{2}\right)$. Consider now the effect of a small increase in $\sigma_{u}^{2}$ above $\sigma_{u}^{2}$. This causes an increase in the costs of imprecise policy procedures since $(1+q) \sigma_{u}^{2}$ goes up. However, if $d$ decreases when $\sigma_{u}^{2}$ goes up, the term $E\left(x_{0}-c_{0}\right)^{2}$ goes down, attenuating this effect. ${ }^{11}$ The intuition is that a higher level of ambiguity, by reducing $d$, makes it possible for the incumbent to choose a policy that is closer to its period 0 ideal because the marginal effect of current policies on expectations is smaller. More importantly, an increase in $\sigma_{u}^{2}$ above $\sigma_{u}^{2}$ may increase the last (positive) term on the right-hand side of (20) by sufficiently reducing $x_{1}^{e}$. When the last two effects dominate the first one, it pays for the incumbent to choose a $\sigma_{u}^{2}$ above $\sigma_{u}^{2}$. The following proposition establishes that the set of parameters for which this is the case is nonempty.

Proposition. There exists a nonempty set of parameter values, including values of $\delta>0$ (risk-averse voters), for which party $x$ chooses a level of ambiguity above the technologically attainable minimal level.

Proof. Suppose first that $\delta=0$. It is sufficient to show that there exists a set of parameter values, including a value of $\sigma_{u}^{2}$, such that for values of $\sigma_{u}^{2}$ slightly above $\underline{\sigma}_{u}^{2}$ the expected value of $J(\cdot)$ is higher. Computer simulations show that the following parameter values, among many others, are in this set: $b_{\epsilon}=q=h=1 ; \alpha=0.5$; $\bar{c}=k=1.5 ; \rho=0.4 ; b /(b-\mathrm{a})=0.5 ; \underline{\sigma}_{u}^{2}=0.07$. These parameter values also imply a unique real solution for $d$, which is $d=0.42$. A simple continuity argument establishes that some level of ambiguity above the minimum is preferred for the same parameters even for some positive (but possibly not too large) values of $\delta$.

Q.E.D.

11. From (3), (4), and (18),

$$
E\left(x_{0}-c_{0}\right)^{2}=d^{2}(q K)^{2}\left[\left(\frac{1}{2}\right)\left(\bar{c}^{2}+(1+\rho)^{2}\right)\left(\frac{b_{\epsilon}^{2}}{3}\right)+(1-\alpha) \frac{h}{\alpha}\right] .
$$

It follows that if $d$ decreases when $\sigma_{u}^{2}$ goes up, so does $E\left(x_{0}-c_{0}\right)^{2}$ We did not prove that $d$ is always decreasing $\mathrm{m} \sigma_{u}^{2}$ However, numerous computer simulations indicate that this is the more likely case. 
Equation (20) highlights which parameter values make ambiguity more or less attractive. A low level of $q$ implies that the benefits of ambiguity are small. In this case party $x$ does not care much about the future benefits of being in office, but it suffers today because of imprecise control of the policy instrument. When $k$ tends to zero, the benefit of ambiguity disappears. From (20) and footnote 11 it is apparent that when $k=0$, the only terms in which $\sigma_{u}^{2}$ appear are the "costs" of ambiguity.

The higher is $\delta$, the lower are the benefits of ambiguity. Ceteris paribus the more risk averse are the voters, the more they dislike the uncertain candidate. ${ }^{12}$ This result can be illustrated in terms of Figure I. For given $\sigma_{u}^{2}$, the incumbent can strategically influence $x_{1}^{e}$, and in doing so, he moves along the given line in that figure. If $\sigma_{u}^{2}$ can be chosen, the policymaker can also affect the position of the downward sloping line, since $\sigma_{u}^{2}$ affects $V$ which determines $K_{u}$ (see equation (14) and Appendix 1 for derivation). An increase in $\sigma_{u}^{2}$ moves the straight line down, reducing the probability of reelection of the incumbent for every $x_{1}^{e}$. However, with a higher $\sigma_{u}^{2}$ the incumbent is able to move more toward zero along a given line. If the shift down (i.e., $\delta$ ) is small, the last effect dominates the downward shift in the curve, and some ambiguity is preferred.

Shepsle [1972] finds that a rational incumbent who only cares about being in office will never choose to be ambiguous if voters are risk averse. In the context of our model, Shepsle's result can be restated by noting that if party $x$ maximizes the probability of reappointment, i.e., $\alpha=0$, and voters are risk averse, the optimal degree of ambiguity is, in fact, zero.

\section{EMPIRICAL SUPPORT}

The model has three basic empirical implications. The first is that voters' views and subsequent voting actions are influenced by policy outcomes during the incumbency of an office holder. The second is that an incumbent tends to choose policies that represent a compromise between his ideological position and that of the challenger in order to fuzz his true position. Finally, for some configurations of voters' distribution and of ideological positions of the parties, the incumbent finds it advantageous to devise institu-

12 If $\delta<0$, the benefits of ambiguity are obviously higher than when $\delta \geq 0$ 
tions that do not fully reveal its true ideological position to the public.

The first implication is consistent with the widely documented observation that individuals vote retrospectively; that is, they judge the incumbent on the basis of policy outcomes during the office period. In particular, the voters evaluate the incumbent on the basis of current and lagged economic conditions (see for instance, Kramer [1971], Fair [1978, 1988], and Fiorina [1981]). Note that there is a widespread view that retrospective voting is inconsistent with voters' rationality [Nordhaus, 1989]. Our model reconciles this widely observed behavior with voters' rationality. ${ }^{13}$

The second implication is consistent with evidence showing that policy responds to public opinion not only when an administration changes but also within the term of office of an administration. Page and Shapiro [1983] examine public opinion and actual policy data for the United States from 1935 to 1979 and find considerable congruence between changes in the public's preferences and actual policies especially for large stable opinion changes. They also present evidence suggesting that more often than not causality runs from public opinion to actual policy rather than in the reverse direction. This is broadly consistent with our analysis since the model implies that when, at the margin, voters' preference shift away from the incumbent's ideological position ( $k$ increase), he will often adjust his policy in the same direction even if his ideological position did not change.

Furthermore, it is often the case that modern political parties try to appeal to a broad group of voters by being vague about the preferences of the party leadership, stressing the common interest of disparate constituencies and deemphasizing basic conflicts among them. The political science literature refers to them as "catchall parties." The term has been coined by Kirchheimer [1966], who drew attention to the fact that in the post-World War II period many European parties underwent a transformation from parties with precisely focused ideologies to catchall parties. In order to attract a maximum number of voters on election day, catchall parties embrace general programs that are sufficiently universal and vague to elicit wide support. "Concrete proposals ... always risk

13. In addition, our model implies that rational retrospective voters should evaluate economic outcomes in ways that depend on the identity of the incumbent, for instance, they may view the Republican Party as more concerned with inflation and the Democratic Party as more concerned with unemployment. Convincing evidence supporting this view is presented by Kıwieit [1981]. 
implying promises which may be too specific. Concretizations must remain general enough so that they cannot be turned from electoral weapons to engines of assault against the party which first mounted them" [Kirchheimer, p. 197]. Kirchheimer also notes that an important function of catchall parties is "the nomination of candidates for popular legitimation as officeholders" [p. 198]. These statements are clearly consistent with the second implication of the model. When a party is in office, it does not fully converge to the ideological position of its leadership in order to maintain its appeal with a sufficient number of voters. And this is partly achieved by acting in ways that do not fully reveal the party's preferred position particularly with respect to controversial issues.

There are no doubt many examples of cases in which incumbents temporarily implemented policies that did not quite match their positions on the issues in order to maintain broad support for their policies. In doing so, they often blurred their positions on the issues. These cases are usually not well documented precisely because accurate documentation defeats the basic purpose which is to masquerade. A dramatic and uncharacteristically well-documented example is the strategy followed by Roosevelt in implementing and presenting his foreign policy to the American public during the last phases of the second world war. Roosevelt believed that the postwar security of the world should rely mostly on agreements and coordination among the big powers rather than on a system of collective security based on the creation of another, stronger League of Nations. This approach required the willing cooperation of the Soviet Union, which in view of the latter's attitude toward selfdetermination for Eastern Europe was very likely to contradict the principles of self-determination and independence that had been written into the Atlantic Charter. Roosevelt was well aware of this dilemma but refrained from educating the American public on the matter in order to maintain legitimacy for his policy. This is succinctly summarized by George, who notes:

Although he strongly favored the Four Policemen concept, Roosevelt was most cautious in publicizing it. He did not seriously attempt to inform and educate public opinion on the matter because he feared that such an effort would shatter the domestic consensus for an internationalist postwar foreign policy. Roosevelt felt he had to blur the difference between his realistic approach to power and security, and the Wilsonian idealists' desire for a system of collective security based on the creation of another, stronger League of Nations. Roosevelt did speak about his Four Policemen concept privately with a number of influential opinion leaders. But when he attempted to float a trial balloon to publicize the idea in an interview with a journalist, it triggered a sharply negative reaction at home from the idealists. As a 
result Roosevelt backed away from further efforts to educate public opinion in order to gain understandıng and legitimacy for his Four Policemen concept [1980, p. 245].

That Roosevelt was acting in this way with electoral considerations in mind is well documented. During the Teheran conference he met privately with Stalin and urged him to agree to have elections in Poland on the grounds that there were six or seven million Polish-Americans in the United States and that Roosevelt "as a practical man did not wish to lose their vote" [Gaddis, 1972, p. $138]$.

The third implication of the model - that incumbents may choose ambiguous procedures for implementing and disseminating their policies-is consistent with the following observations. Different procedural rules affect how voters can "see through" and attribute specific positions to various congressmen or to the administration. For instance, an important development in the U.S. legislative process has been an increase in the use of delegation to committees and subcommittees. The increasing legislative role played by committees has been referred to as a "puzzle."14 Our model can explain the "puzzle" as a way to make it harder for the electorate to pinpoint which legislator is reponsible for which piece of legislation. By avoiding explicit roll call voting in Congress, legislators are not forced to openly take a position on every issue and can maintain a certain degree of "ambiguity" about their ideology. An additional way to blur the party's ideological preference is to appoint officeholders whose positions on the issues are known to be distant from that of the party leader. A related observation is that Presidential candidates are often "embarrassed" by their voting record if they were Senators or Representatives before being Presidential candidates. This "embarrassment" arises because it makes it harder to fuzz the candidate's position.

A similar argument may apply to the role played by relatively independent central banks like the Federal Reserve. Given the Fed's institutional independence, Presidential influence on the conduct of monetary policy has traditionally been informal and relatively "secret." This "secrecy" may actually be advantageous for politicians, since it allows them to be "ambiguous" about their true objectives. For instance, a monetary "conservative" administration may appear more "moderate" by claiming to be pursuing

14. See Shepsle and Weingast [1987] and the references quoted therein for a general discussion 
economic growth, while it is fully supportive of a contractionary policy for which the central bank is blamed. This is consistent with Kane's [1980] thesis according to which the Fed performs a "scapegoat" function for politicians.

The degree of ambiguity chosen by the incumbent should depend, according to our model, on the marginal loss in reelection probability caused by a movement toward the incumbent's ideal policy. This marginal loss is captured by the parameter $k$. As shown in Section IV, the direct effect of low values of $k$ imply a more "ideological" policy choice. Also, as shown in Section V, the benefit of ambiguity vanishes when $k$ becomes very low. Thus, administrations that are "popular," in the sense that they do not lose much support "regardless" of what they do, could be expected to be more ideological and less ambiguous in their policies. This is perhaps the case of the administration of President Reagan, who was a particularly "popular" president and the Thatcher governments in the United Kingdom (in the latter case the "popularity" of the incumbent should be judged relative to the disarray of the opposition).

More generally, the candidates' goal to be "ambiguous" about their true ideology can also explain why in electoral campaign statements positions are often "vague." In fact, as noted by Shepsle [1972], the most common recommendation of professional consultants to candidates is not to be too concrete, at least up to a point. Political strategists believe that the best candidate is someone whose "character" is sufficiently well-known by the voters, but whose voting and political record is not too transparent ideologically. Even though our model does not directly address the issue of campaign advertising, its basic message is consistent with this observation. By contrast, models implying that candidates should minimize their variance to please risk-averse voters are at odds with it.

\section{CONCLUSIONS}

The results of this paper can be summarized by four points.

First, the paper characterizes the degree of policy convergence in a two-party system for the realistic situation in which an incumbent is more informed than the voters about his own preferences.

Second, the paper shows that if the incumbent can choose the level of ambiguity, he may not choose to eliminate it completely even if voters are risk averse. In fact, by choosing to be somewhat 
ambiguous, the incumbent can improve his trade-off between ideological and electoral goals. It is instructive to relate this result to that of Cukierman and Meltzer [1986b]. They show that central bankers may choose to make policy procedures governing the money supply less precise than technically feasible. In that model ambiguity enables policymakers to take better advantage of a short-run trade-off between inflation and unemployment. ${ }^{15}$

Third, this paper suggests a positive theory of delegation. One way in which policymakers can introduce "ambiguity" about their policy actions is by creating and using various partially independent agencies. The latter can be used by the politicians as scapegoats and, more generally, as a means of making the decision process and the incumbent's preferences less transparent.

Fourth, the paper demonstrates that retrospective voting is not inconsistent with the assumption of voters' rationality. ${ }^{16}$

There is a formal resemblance between the deliberate creation of noise in the implementation of policy in this paper and mixed strategies in game theory. However, the analogy in more apparent than real. With mixed strategies players are indifferent between the various pure strategies used to construct the mixed strategy. As a matter of fact, they are even indifferent between all possible mixtures of those pure strategies. By contrast, in our framework the incumbent strictly prefers noise to precise control procedures in the implementation of policy for appropriate sets of parameter values.

Even though our results have been obtained in a two-period model, we speculate that the extension to the infinite horizon should not qualitatively change their nature. In fact, in our model the incumbent chooses to "converge" and to be ambiguous to enhance his chances of reappointment. With an infininte horizon this incentive would always be present, since there is no last period. Thus, partially convergent and ambiguous behavior should persist beyond the first period. This extension, however, introduces an additional dimension in the game, having to do with the strategic interaction between the two parties that alternate in office in a repeated sequence of elections (see Alesina [1988]).

Finally, we have assumed that the position of the challenger is known with certainty. In fact, voters may be rather poorly informed

15. Tabellin [1988] shows that Central Bank secrecy may be optimal for a smooth functioning of financial markets

16 The papers by Cukierman and Meltzer [1986a], Rogoff and Sibert [1988], and Rogoff [1990] have a similar implication although in different settings. 
about the preferences of the candidate who is out of office [Bernhardt and Ingberman, 1985]. Allowing exogenous uncertainty about the challenger's position is an easy extension that just shifts the entire probability of being elected in favor of the incumbent. In fact, ceteris paribus, risk-averse voters would react negatively to an increase in the uncertainty about the challenger. As a consequence, the set of parameters for which ambiguity is beneficial to the incumbent increases, strengthening our ambiguity result. However, when the challenger can send credible signals about his postelection policy, the extension is not as immediate. Such an extension must await further work.

Appendix 1: Derivation of the Probability function $P\left(x_{1}^{e}, 0\right)$

Under assumptions A.1 through A.4 in the text, the expected utility of a voter with ideal point $i$ from the incumbent and the challenger is given, respectively, by

$$
\begin{gathered}
-\left\{\left|x_{1}^{e}-\imath\right|\right\}+\delta V \quad \delta \geq 0 \\
-|i| \quad \text { (since } y_{1}^{e}=0 \text { with certainty). }
\end{gathered}
$$

The stochastic position of the ideal policy of the median voter $\left(i_{m}\right)$ is given by

$$
i_{m} \sim U(a, b) \quad a<0, \quad b>0,
$$

where $U$ stands for the uniform distribution. Since voters have single picked symmetric preferences, the outcome of the election is decided by the median voter. (A1) and (A2) imply that he votes for the right-wing candidate if and only if

$$
\left|i_{m}\right|-\left[\left|x_{1}^{e}-i_{m}\right|+\delta V\right]>0 .
$$

Note that $V$ is independent of the realizations of the stochastic shocks $\eta$ and $u$ and therefore of $x_{1}^{e}$ as well. Let $i_{c}$ be an ideal point such that (A4) holds with equality. Equation (A4) implies that all voters with ideal points that are larger than or equal to $x_{1}^{e}$ vote for the left-wing candidate if and only if

$$
x_{1}^{e}-\delta V \leq 0 .
$$

It is possible to show, by contradiction, that assumption A.4 in the text implies that $i_{c}<x_{1}^{e}$, (details are available from the authors 
upon request) and thus that

$$
i_{c}=\frac{1}{2}\left(x_{1}^{e}+\delta V\right) .
$$

The probability that the right-wing candidate is elected is equal to

$$
1-\int_{a}^{\iota_{c}} \frac{1}{b-a} d i_{m}=\frac{b}{b-a}-\frac{i_{\mathrm{c}}}{b-a} .
$$

Substituting (A6) into (A7) and rearranging, we obtain (14) in the text.

Note that since $b>a, k>0$. In addition, since (by Assumption A.4 in the text) for sufficiently small but positive $x_{1}^{e}$ the probability that the right-wing party is elected is positive, $K_{u}$ is positive as well. Since $\delta V>0$ and $a<0, K_{u}<1$. If $x_{1}^{e}=0, P\left(x_{1}^{e}, 0\right)=1 / 2 . K_{u} \geqslant 1 / 2$, depending on whether $b$ is large or small in comparison to $|a|$ and $V$.

\section{Appendix 2: Derivation of the Optimal Predictor}

The parameters $d$ and $f$ are determined so as to minimize

$$
V \equiv E\left\{\left[x_{1}-\left(f+d z_{0}\right)\right] \mid z_{0}\right\}^{2} .
$$

Since $c_{-1}=\bar{c}$, it follows that

$$
\eta_{0}=\epsilon_{0} ; \quad \eta_{1}=\rho \epsilon_{0}+\epsilon_{1} .
$$

Since $c_{-1}=\bar{c}$ and $\epsilon_{t}$ is uniform, (3), (4), and (A9) imply that

$$
\text { (A10) } E^{G}\left(c_{1}\right)^{2}=E\left[\left(\bar{c}+\rho \epsilon_{0}+\epsilon_{1}\right)^{2} \mid \epsilon_{0}\right]=\bar{c}^{2}+b_{\epsilon}^{2} / 3+\rho^{2} \epsilon_{0}^{2}+2 \rho \bar{c} \epsilon_{0} \text {. }
$$

Using (5), (18), (A8), and (A10) in (A8), $d$ and $f$ are determined by

$$
\min _{d, f} E\left\{\left[\bar{c}+\rho \epsilon_{0}+\epsilon_{1}-f-d\left(A+B \epsilon_{0}-D \epsilon_{0}^{2}+u_{0}\right)\right]^{2} \mid z_{0}\right\},
$$

where

$$
\begin{aligned}
& A \equiv \bar{c}-q k\left[\frac{1}{6}\left(3 \bar{c}^{2}+b_{\epsilon}^{2}\right)+\frac{1-\alpha}{\alpha} h\right] d ; \\
& B \equiv 1-q k \rho c d ; \quad D \equiv \frac{1}{2} q k \rho^{2} d .
\end{aligned}
$$

Equations (16) and (17) in the text are obtained by solving the minimization problem in (A11) and by straightforward (but tedious) algebraic manipulations. If the following sufficient condition 
holds:

$$
\left[3 q k\left(\rho b_{\epsilon}\right)^{2} \bar{c}+9 \sigma_{u}^{2} / b_{\epsilon}^{2}-1\right] \bar{c}+\frac{3}{5} q k\left(\rho b_{\epsilon}\right)^{4}>0,
$$

there is only one real solution for $d$ and thus one for $f$. A more detailed version of this Appendix is available from the authors upon request.

HaRvard University, National BureaU of Economic Research, and CENTER FOR ECONOMIC POLICY RESEARCH

Tel-Aviv University, AND Princeton University

\section{REFERENCES}

Alesina, Alberto, "Macroeconomic Policy in a Two-Party System as a Repeated Game," Quarterly Journal of Economics, CII (1987), 651-78.

"Crediblity and Policy Convergence in a Two-Party System with Rational Voters," Americar Economic Review, LXXVIII (1988), 796-806.

, and Stephen Spear, "An Overlapping Generations Model of Political Competition," Journal of Publuc Economics, XXXVII (1988), 359-79.

Bernhardt, Daniel, and Daniel Ingberman, "Candidate Reputation and Incumbency Effect," Journal of Public Economics, XXVII (1985), 47-67.

Calvert, Randall, "Robustness of the Multıdimensional Voting Model: Candidates' Motivations, Uncertainty and Convergence," American Journal of Political Science, LXXIX (1985), 1056-70.

Cukierman, Alex. "Asymmetric Information and the Electoral Momentum of Public Opinion Polls," Public Choice, vol. no. (1990), forthcoming. , and Allan Meltzer, "A Positive Theory of Discretionary Policy, the Cost of a Democratic Government and the Benefits of a Constitution," Economic Inquiry, XXVI (1986a), 367-88.

, and "A Theory of Ambiguity, Credibility and Inflation Under Discretion and Asymmetric Information," Econometrica, LI (1986b), 1099-1128.

Downs, Anthony, An Economic Theory of Democracy (New York: Harper and Row, 1957).

Fair, Ray, "The Effects of Economic Events on Votes for President," Review of Economics and Statistics, LX (1978), 195-72.

"The Effect of Economic Events on Votes for President' 1988 Update," NBER Working Paper No. 2222, December 1988

Fiorina, Morris, Retrospective Voting in American Natıonal Elections (New Haven: Yale University Press, 1981).

Gaddis, John L, The United States and the Origins of the Cold War, 1941-1947 (New York. Columbia University Press, 1972).

George, Alexander L., "Domestic Constraints on Regime Change in U. S. Foreign Policy: The Need for Policy Legitimacy," in Ole R Holsti, Randolph M. Siverson, and Alexander L. George, eds., Change in the International System, (Boulder, CO: Westview Press, 1980), pp. 233-62.

Kane, Edward J., "Politics and Fed Policymaking: The More Things Change the More They Remain the Same," Journal of Monetary Economics, VI (1980), 199-212.

Kiwielt, Roderick, Macroeconomics and Micropolttucs (Chicago: University of Chicago Press, 1984).

Kirchheimer, Otto, "The Transformation of the Western European Party Systems," in Joseph La Palombra and Myron Weiner, eds., Political Partıes and Polttıcal Development (Princeton: Princeton University Press, 1966).

Kramer, Gerald, "Short-term Fluctuations in U. S. Voting Behavior," American Political Science Review, IXXV (1971), 448-59.

Lott, John, and Robert Reed, "Shirking and Sorting in a Political Market with Finite Lived Politicians," unpublished, 1987. 
Nordhaus, William, "Alternative Models of Political Busıness Cycles," Brookings Papers on Economic Activity (1989:2), 1-68.

Page, Benjamin I, and Robert Y. Shapiro, "Effects of Public Opınion on Policy," American Politıcal Science Review, LXXVII (1983), 175-90

Rogoff, Kenneth, "Equihbrium Political Budget Cycles," American Economic Review, LXXX (1990), 21-36 , and Anne Sibert, "Equilibrium Political Business Cycles," Revıew of Economic Studies, LV (1988), 1-16.

Shepsle, Kenneth, "The Strategy of Ambiguity: Uncertainty and Electoral Competition," American Political Scıence Review, LXVI (1972), 55568.

_. and Barry Weingast, "The Institutional Foundation of Committee Power," American Political Science Review, LXXXI (1987), 85-104.

Stein, Herbert, Presidentıal Economics (New York. Simon and Schuster, 1985).

Tabellinı, Guido, "Secrecy of Monetary Policy and the Variability of Interest Rates," Journal of Money, Credit and Banking, XIX (1988), 425-36.

Wittman, Donald, "Candidate Motivation" A Synthesis of Alternative Theories," American Political Science Review, LXXVII (1983), 142-57. 